Article

\title{
Analytical Method for Lithium Isotopes Determination by Thermal Ionization Mass Spectrometry: A Useful Tool for Hydrogeochemical Applications
}

\author{
Ilenia Arienzo ${ }^{1, *}$, Marcello Liotta ${ }^{2}\left(\mathbb{D}\right.$, Lorenzo Brusca ${ }^{2}$, Massimo D'Antonio ${ }^{3}$, Federica Lupone ${ }^{1}$ \\ and Ciro Cucciniello ${ }^{3}$ (D) \\ 1 National Institute of Geophysics and Volcanology, Osservatorio Vesuviano, Via Diocleziano 328, \\ 80124 Naples, Italy; fedelu91@gmail.com \\ 2 National Institute of Geophysics and Volcanology, Sezione di Palermo, Via La Malfa 153, \\ 90146 Palermo, Italy; marcello.liotta@ingv.it (M.L.); lorenzo.brusca@ingv.it (L.B.) \\ 3 Department of Earth, Environmental and Resources Sciences (DiSTAR), University of Naples Federico II, \\ Complesso Universitario di Monte Sant'Angelo, Via Cintia 21 (edificio L), 80126 Naples, Italy; \\ masdanto@unina.it (M.D.); ciro.cucciniello@unina.it (C.C.) \\ * Correspondence: ilenia.arienzo@ingv.it; Tel.: +39-081-6108441
}

Received: 8 July 2020; Accepted: 31 July 2020; Published: 3 August 2020

\begin{abstract}
The low temperature realm such as the geothermal systems, characterized by a large variety of near-Earth surface processes, has been the object of several isotopic studies, some of them including lithium isotopes. However, much work can still be done to systematically use lithium as tracer of geochemical processes in deep and shallow Earth reservoirs. A pilot study has been performed for the determination of lithium-isotope ratio by thermal ionization mass spectrometry (TIMS), a technique poorly employed with respect to other methods such as inductively coupled plasma mass spectrometry, being more time consuming. Lithium has been extracted by chromatographic techniques on columns through an ion exchange process from both natural and reference samples. The isotope composition $\left({ }^{6} \mathrm{Li} /{ }^{7} \mathrm{Li}\right)$ expressed in terms of $\delta^{7} \mathrm{Li}$ has been determined in dynamic and static mode for comparative purposes, by using two different types of thermal ionization mass spectrometers. The results presented in this work agree with the data reported in the literature, opening a new perspective to future research on continental geothermal systems and groundwater domains, spread over the entire Italian peninsula. This research is based on the use of chemical and isotopic data, whereas it does not include lithium isotopes. These latter may provide a huge contribution in studying both volcanic products and fluids from active volcanic areas, including the superposed geothermal systems, and may represent a new tool for research and surveillance.
\end{abstract}

Keywords: TIMS; ${ }^{6} \mathrm{Li} /{ }^{7} \mathrm{Li}$ ratio; analytical methods; reference materials

\section{Introduction}

Geochemical and isotopic data represent a useful tool for understanding how the Earth system works and solving several geological issues. The combination of data relative to major and trace elements, radiogenic (e.g., $\mathrm{Sr}, \mathrm{Nd}, \mathrm{Pb}$ ) and stable (e.g., $\mathrm{H}, \mathrm{O}, \mathrm{B}$ ) isotope compositions, allows distinguishing the effects of different processes when dealing with environmental and volcanological studies and provides important clues on Earth's genesis, magma reservoirs and their dynamics. J. A. Arfvedson discovered lithium as an elemental species in 1817 [1]. Lithium (Li) has two naturally occurring stable isotopes: ${ }^{6} \mathrm{Li}$ and ${ }^{7} \mathrm{Li}$. Their atomic abundances in natural sources are approximately 
$7.6 \%$ and $92.4 \%$, respectively [2,3]. For several decades, many investigators have studied the isotopic composition of lithium in an effort to determine the natural variation of its isotopic abundance $[4,5]$. The two isotopes are susceptible to separation (i.e., fractionation) in several natural processes including mineral formation (chemical precipitation), cation substitution (lithium substitutes for $\mathrm{Mg}$ and $\mathrm{Fe}$ in octahedral sites in micas and clay minerals, where ${ }^{6} \mathrm{Li}$ is preferentially hosted over ${ }^{7} \mathrm{Li}$ ) and rock alteration, due to their relatively large difference in mass. Moreover, ${ }^{7} \mathrm{Li}$ preferentially partitions into aqueous fluids relative to mafic minerals, giving waters higher $\delta^{7} \mathrm{Li}\left(\left[\frac{\frac{7 L i}{6 L i} \text { sample }}{\frac{7 L i}{6 L} \text { standard }}-1\right] \times 1000\right)$ values compared to mafic rocks [6]. Several experimental studies on mineral-fluid partitioning [7-9] showed that the isotopic fractionation of lithium between phases is also a function of temperature. Diffusion is the second way in which isotopes become fractionated in nature. In this case, one isotope is transported more rapidly than another in processes such as evaporation or diffusion along a chemical potential gradient. In experiments, for example, lithium fractionation is produced by a faster diffusion of ${ }^{6} \mathrm{Li}$ (up to $3 \%$ ) with respect to ${ }^{7} \mathrm{Li}$ in both silicate melt and water [10,11]. In addition to natural fractionation, isotopic separation during chemical preparation and instrumental analyses can contribute to the measured values. However, considerable progresses have been recently made to minimize mass fractionation during analysis.

In the last few decades, lithium isotopes have been investigated to reveal important information concerning a wide range of processes, such as hydrothermal activity, alteration of the oceanic crust, and riverine variability [6,12-15]. Coupled with boron isotope systematics [16], lithium isotopes can provide information on the role and nature of the recycled crustal materials in a mantle source and on the metasomatism of a mantle wedge [17-22]. Lithium isotopes can also be useful as tracer of degassing processes $[23,24]$ and, coupled with Fe isotope systematics [25], have become used in high temperature geochemistry to study planet formation and magmatic differentiation. Moreover, lithium isotope systematics has been applied to study isotope geochemistry of sediments and hydrothermal fluids of the Guaymas Basin (Gulf of California) [26] and of thermal waters from Yellowstone National Park [27]. In this latter case, lithium isotopes have been used to distinguish water derived from marine sedimentary rocks from water derived from hydrothermally altered igneous rocks, thereby providing valuable information regarding regional ground-water flow paths. Lithium isotopes have also been measured on island arc volcanics from the Izu arc, Japan, to investigate geochemical processes in subduction zones [17] and applied to study the ocean islands magma source and to discriminate between the contribution of the HIMU and non-HIMU mantle sources to the melt production in the Austral Chain [21].

Studies dealing with the lithium isotopic composition of atmospheric precipitation suggest that lithium in the marine source does not necessarily dominate the composition of rainfall [28]. The effects of the interaction between water and sediments were studied by [29-31]. With prolongation of water-sediment interaction, lithium is removed from groundwaters, and the isotopic signature shifts to lightest values. Négret et al., 2012 [32], showed that the groundwaters of southwestern France were characterized by mixing between rainwaters of variable $\delta^{7} \mathrm{Li}$ and waters carrying an imprint of interaction with sediments or rocks featured by lowest $\delta^{7} \mathrm{Li}$. A novel approach was proposed by Millot and Négrel (2007) [33] studying French geothermal waters. The authors suggested that lithium isotopes could be used as a geothermometer. Falkner et al., 1997 [34], showed the potential of lithium isotopes as a tool for understanding weathering processes. In fact, lithium released during weathering is isotopically heavier than that present in minerals of the un-weathered rocks. Similar results were found studying young, pristine basalts from active ocean ridge crests. These samples have $\delta^{6} \mathrm{Li}$ values of between -3.4 and $-4.7 \%$ [6]. The effect of low-temperature weathering is to modify their isotope composition toward the seawater value due to addition of seawater-derived lithium in the alteration minerals. Finally, geothermal systems have been the subject of several lithium isotopic studies both on the continents and in the oceans, e.g., [6,35-38].

In this context, encouraged during the last 10 years by the explosion of the lithium-based research, we carried out the study titled "Lithium isotopes as tracers of crust/mantle interaction at subduction 
zones; understanding the evolution of the Plio-Quaternary volcanic areas of Central Italy: a pilot study". This study was proposed in the framework of the Italian funding program FISR 2015-2016 "Centro di studio e monitoraggio dei rischi naturali dell'Italia Centrale". It represents a pilot study on the application of Li-isotope systematics to selected igneous rocks, in order to shed new light on the nature of subduction components involved in the genesis of magmas feeding the Roman Magmatic Province (Central Italy). It offered the possibility to set up the procedure for extracting and measuring lithium isotopes, opening new prospective to our research also in studying processes in shallow Earth reservoirs. The present paper, based on work published in 2000 by James and Palmer [39], deals with (1) the techniques that have been used to extract lithium from natural and reference samples, such as the USGS BHVO-2 (batch \#0759), a seawater sample (NA01600m) and the NIST L-SVEC certified international standard and (2) the procedures adopted for measuring lithium isotope compositions by thermal ionization mass spectrometry both in dynamic and static mode.

\section{Materials and Methods}

In order to extract lithium and measure its isotope composition in volcanic products and groundwater, during the period from the 2017 and the beginning of the 2018, we set up the procedure to be used in the clean laboratory of the Istituto Nazionale di Geofisica e Vulcanologia (INGV), Sezione Osservatorio Vesuviano (OV) and in two Thermal Ionization Mass Spectrometry laboratories. Isotope ratio determinations have been performed at the INGV-OV using a Finnigan Multicollector Triton TI ${ }^{\circledR}$ (Thermo Fisher Scientific, Waltham, MA, USA) and at Dipartimento di Scienze della Terra, dell'Ambiente e delle Risorse (DiSTAR)—University Federico II of Napoli, by using a ThermoFisher Triton Plus ${ }^{\circledR}$ (Thermo Fisher Scientific, Waltham, MA, USA) mass spectrometers.

\subsection{Procedure Adopted in the Clean Chemistry Laboratory: Sample Preparation}

Lithium has been separated from other ions in the sample solutions by conventional ion exchange chromatography techniques. Before chemical separation and isotope ratio determinations, the geological samples were dissolved in the Clean Chemistry Laboratory of the INGV-OV, equipped with conditioned (c.a. $23^{\circ} \mathrm{C}$ ) and over-pressured air (Figure 1). Sample dissolution consists in the transformation of constituents, non-dissolvable silicate phases, into soluble phases. This transformation is achieved by acid digestion. For establishing the procedure to apply to lithium isotope measurement of silicate rocks, $0.1 \mathrm{~g}$ of USGS BHVO-2 has been weighted. For samples dissolution, high purity (Suprapur ${ }^{\circledR}$ grade, Merck KGaA, Darmstadt, Germany) hydrofluoric acid (HF, 40 wt.\%), nitric acid $\left(\mathrm{HNO}_{3}, 65\right.$ wt.\%), hydrochloric acid $(\mathrm{HCl}, 30 \mathrm{wt} . \%)$ has been used, together with Milli ${ }^{\circledR} \mathrm{H}_{2} \mathrm{O}$ (Merck KGaA, Darmstadt, Germany). For what concerns water samples, $15 \mathrm{~mL}$ of solution has been placed in Savillex ${ }^{\circledR}$ Teflon beaker (Savillex, Eden Prairie, MN, USA) and dried down on hotplate (c.a. $120^{\circ} \mathrm{C}$ ), before dissolution in hydrochloric acid. 


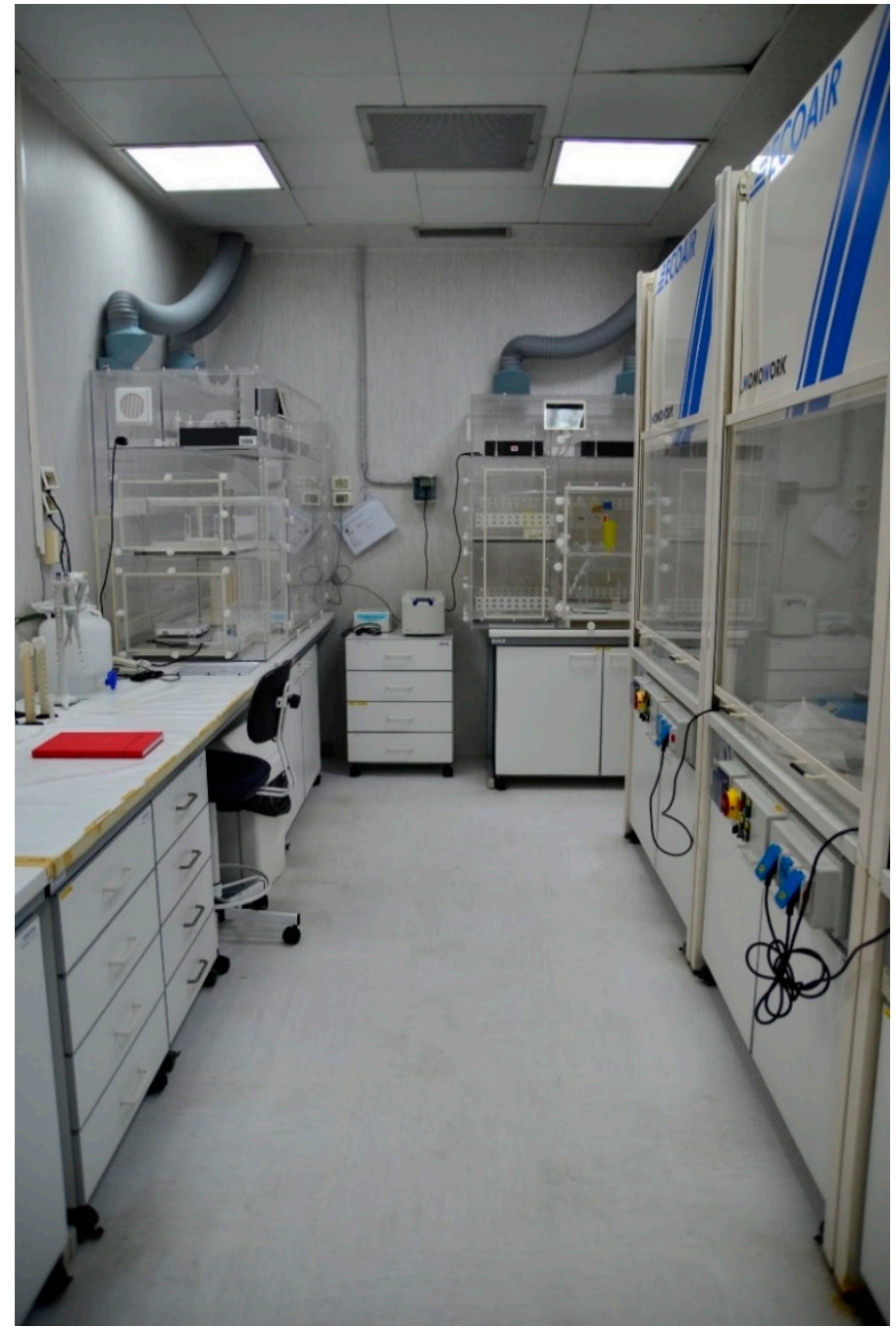

Figure 1. The Clean chemistry laboratory of the Istituto Nazionale di Geofisica e Vulcanologia (INGV), Sezione Osservatorio Vesuviano (OV).

\subsection{Sample Dissolution}

The first step of sample digestion consists in dissolving the weighed amount of sample in concentrated HF. The solution is left in a closed Savillex ${ }^{\circledR}$ beaker (Savillex, Eden Prairie, MN, USA) on a hot plate, at $120^{\circ} \mathrm{C}$ for 1-2 days, in case of whole-rock powder (depending on the particle size), and for 3-5 days for mineral phases; see also [40]. The result of HF interaction with rock derived cations is the formation of fluorides, which are insoluble in $\mathrm{HCl}$. The second dissolution step consists in adding $\mathrm{HNO}_{3}$ that helps to convert the fluorides into nitrates that are soluble in $\mathrm{HCl}$. The solution is again evaporated to dryness on hot plate. The third step consists in dissolving the sample in $6 \mathrm{~N} \mathrm{HCl}$. The solution is left in closed beaker on hot plate for $12 \mathrm{~h}$ at $120^{\circ} \mathrm{C}$.

The seawater and the NIST L-SVEC samples, following evaporation, and the USGS BHVO-2 samples, following chemical dissolution, were re-dissolved in $0.2 \mathrm{~N} \mathrm{HCl}$ and centrifuged for $10 \mathrm{~min}$ at c.a. $5000 \mathrm{rpm}$.

\subsection{Chemical Separation of Lithium}

In order to separate lithium from sample solutions, ion-exchange column chromatographic techniques have been used. Five quartz columns have been set up and calibrated. The stationary bed hosted in the columns (Figure 2) is made up of Dowex AG 50 W X-8 (200-400 mesh) cation exchange resin (Dow Chemical Company, Midland, MI, USA). Columns are conditioned in $0.2 \mathrm{~N} \mathrm{HCl} \mathrm{[39].} \mathrm{To}$ 
calibrate the columns, a sample solution (NIST L-SVEC standard) with 200 ppm lithium was loaded on each column. Then, several aliquots of $0.2 \mathrm{~N} \mathrm{HCl}$ were loaded, each time collecting the eluted aliquots in different labeled tubes. The solutions were analyzed with an Agilent 7500ce (Agilent, Santa Clara, CA, USA), inductively coupled plasma-mass spectrometer (ICP-MS; Figure 3) at INGV, Palermo. We measured the lithium concentrations, in order to know the volume of $0.2 \mathrm{~N} \mathrm{HCl}$ to be eluted and discarded for each column, and the $0.2 \mathrm{~N} \mathrm{HCl}$ volume, containing the lithium fraction, to be eluted and collected into the beakers. The instrument is equipped with a Micromist nebulizer, a Scott double pass spray chamber, a three-channel peristaltic pump and an auto sampler (ASX-500, Cetac, Agilent, Santa Clara, CA, USA). The mass spectrometer was calibrated on ${ }^{7} \mathrm{Li}$ mass, with 8 standard solutions plus blank solution. Each standard solution was prepared by dilution from a single element stock solution with concentration of $1000 \mathrm{mg} / \mathrm{L}$ (Merck). The calibration solutions were prepared daily in $10 \mathrm{~mL}$ polyethylene tubes by dilution using $1 \%$ nitric acid for trace analysis as diluent in the range $0.02-5.00 \mu \mathrm{g} / \mathrm{L}$ (Figure 4).

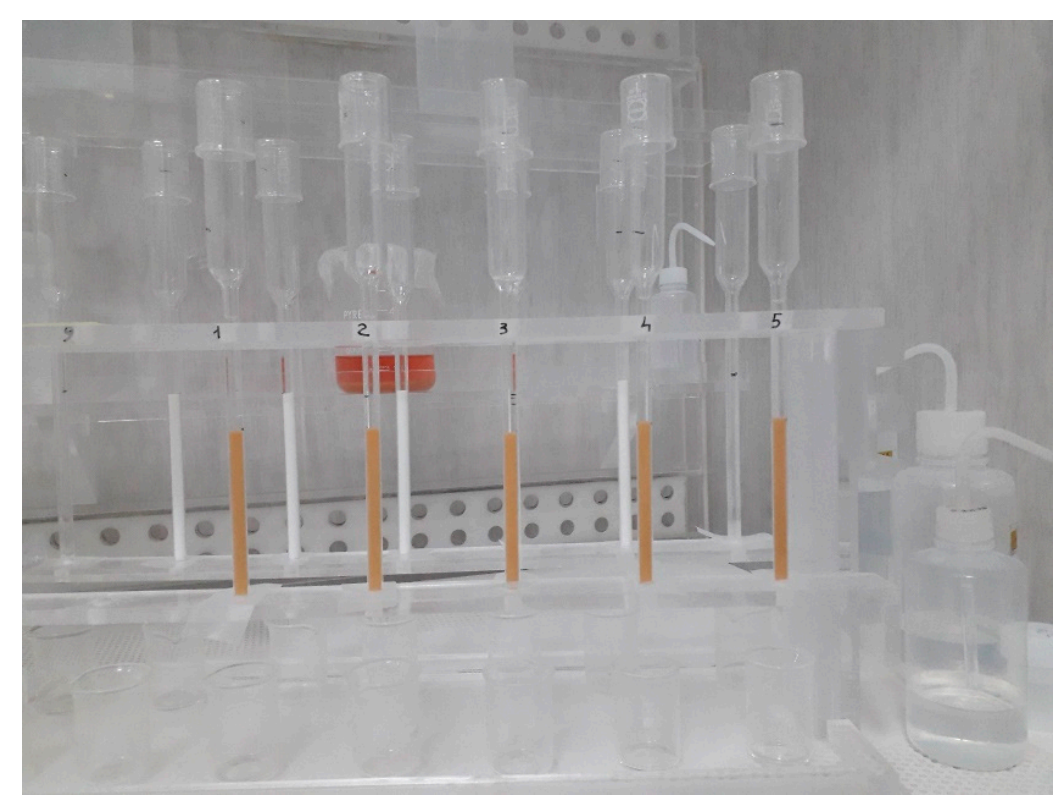

Figure 2. Quartz columns for Li separation by chromatographic techniques.

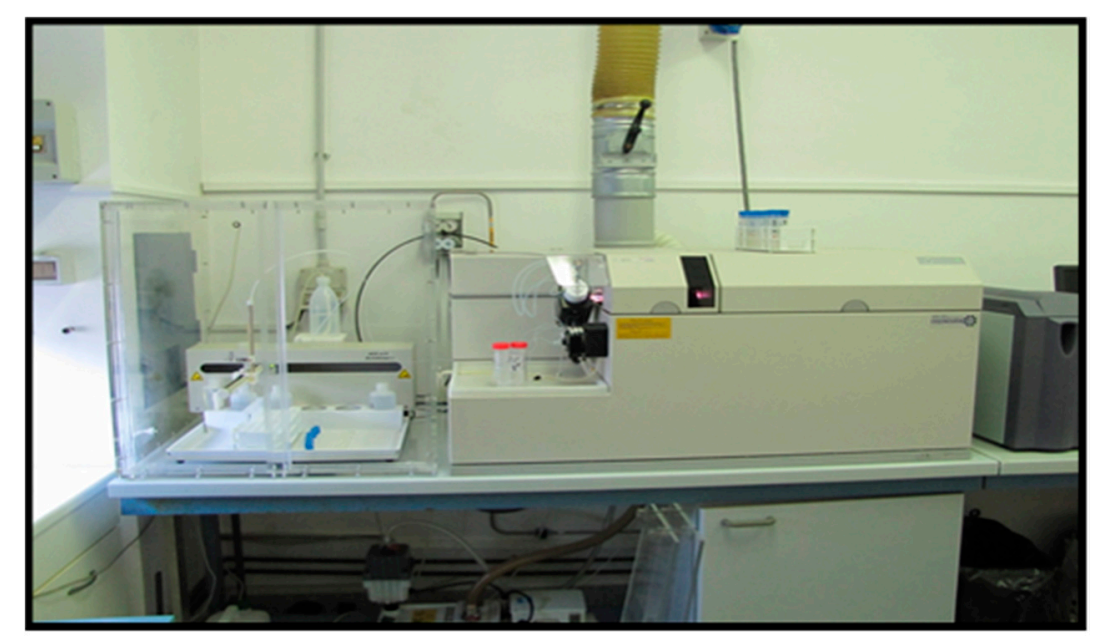

Figure 3. Agilent 7500ce inductively coupled plasma-mass spectrometer (ICP-MS) at INGV, Palermo. 


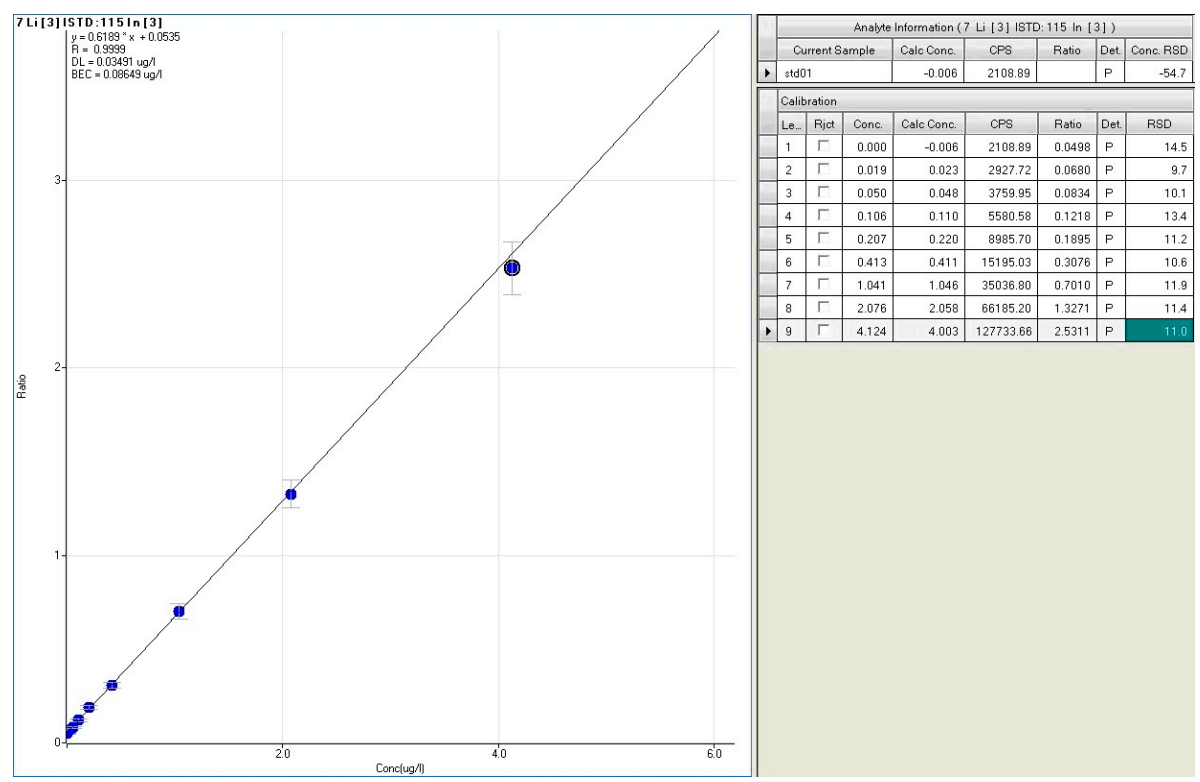

Figure 4. Calibration curve for ${ }^{7} \mathrm{Li}$ mass. The standard solutions were prepared by dilution from single element stock solution at $1000 \mathrm{mg} / \mathrm{L}$, plus blank solution.

The sensitivity variations were monitored using ${ }^{115}$ In as internal standard. An appropriate device that mixes the internal standard solution into the sample just before the nebulizer was used in order to add the standard directly online. The concentration of the internal standard was about $10 \mu \mathrm{g} / \mathrm{L}$ in all sample and calibration solutions. The precision of the analysis was checked by running five replicates of each standard and sample. Data accuracy was evaluated by analyzing standard reference materials (Environment Canada TM 27.3, TM Rain-04 and TM 35) during each analytical session. The precision and the data accuracy were within $\pm 12 \%$ and $<15 \%$, respectively, during the analyses.

On the basis of results of the ICP-MS analyses, we reconstructed the calibration curves relative to each of the five chromatographic columns. Different calibration curves were obtained when loading the NIST L-SVEC standards, the BHVO-2 sample and the seawater sample (Figure 5). For NIST L-SVEC standards and BHVO-2 samples, the calibration curves at $\mathrm{T}=23^{\circ} \mathrm{C}$ and $\mathrm{T}=19^{\circ} \mathrm{C}$ (not shown), display similar volumes of acid to be eluted and discarded (c.a. $10 \mathrm{~mL}$ ) and similar volumes of acid to be collected during elution (c.a. $9 \mathrm{~mL}$ ), implying negligible temperature dependence for the resin. When loading the Na-rich seawater samples, a shift in the column calibration was observed (Figure 5, column 5 , green curve).

\subsection{Procedure Adopted in the Mass Spectrometry Laboratories: Loading of Lithium on Rhenium Filament.}

Once the chemical separation was completed, the collected solutions containing lithium were dried down on a hot plate. A few drops of concentrated $\mathrm{HNO}_{3}$ was then added to the samples and dried down once again. Finally, the lithium fractions were dissolved in 1 or $2 \mu \mathrm{L}$ of diluted $\mathrm{HNO}_{3}$ and loaded on previously degassed rhenium (Re) filaments in a double configuration with another Re filament. The loading procedure consists of the following steps:

(1) Load $1 \mu \mathrm{L}$ solution on a degassed filament and dry it at 1.5-max $2.0 \mathrm{~A}$;

(2) Turn down, before glowing. 


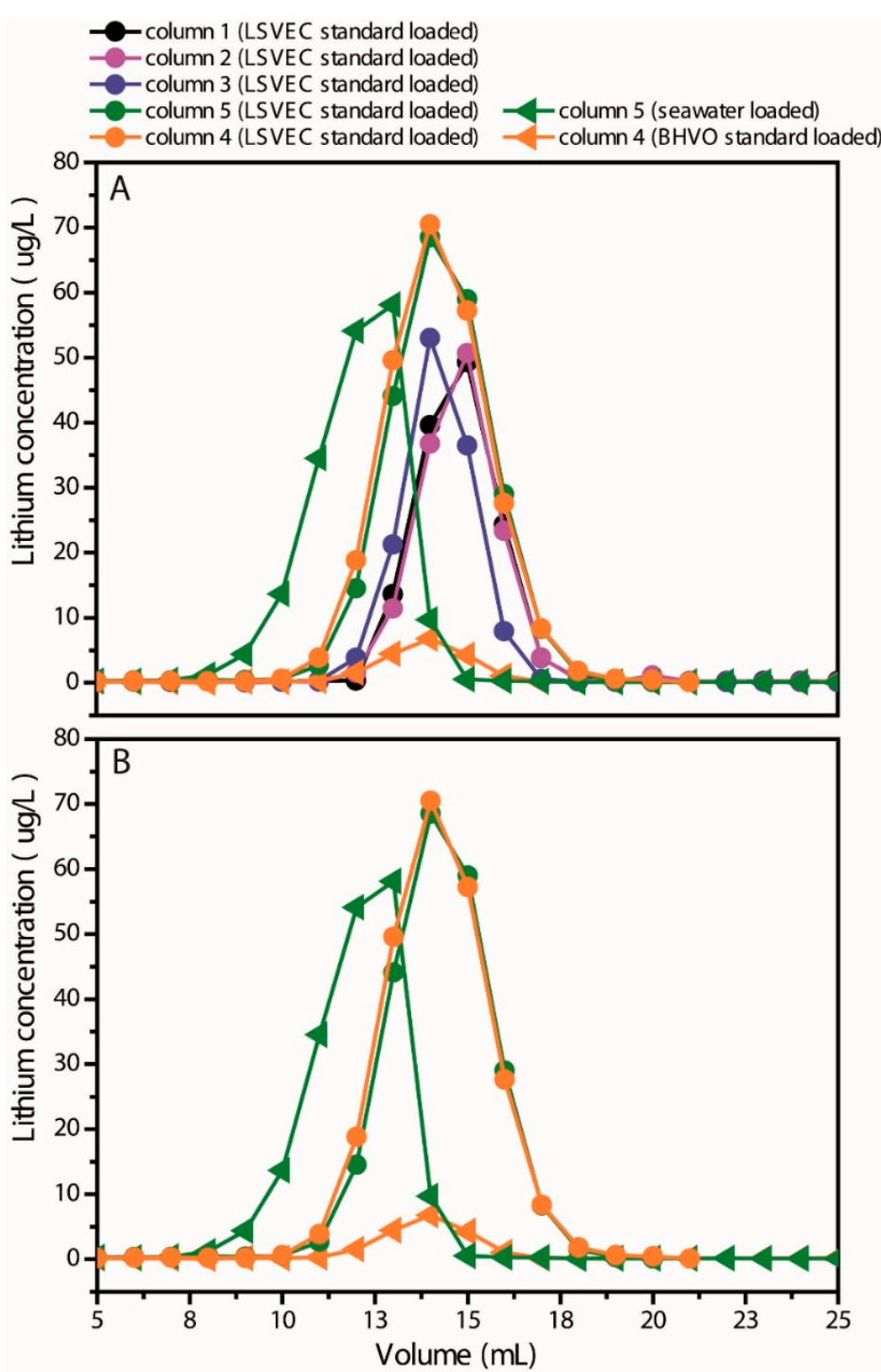

Figure 5. (A) Calibration curves of the chromatographic columns at $\mathrm{T}=23^{\circ} \mathrm{C}$; (B) Detail of the calibration curves of columns 4 and 5 with different, loaded samples.

\subsection{Lithium Isotopic Determinations by Thermal Ionization Mass Spectrometry}

Lithium isotopes were measured by Thermal Ionization Mass Spectrometry (TIMS). Measurements were performed by using the Finnigan Multicollector Triton $\mathrm{TI}^{\circledR}$ at INGV, OV, and the Triton Plus ${ }^{\circledR}$ at DiSTAR (Figure 6). The instruments are in constant temperature rooms $\left(23^{\circ} \mathrm{C}\right.$ and $20^{\circ} \mathrm{C}$, respectively) to allow the sophisticated integrated systems and the amplifiers to work correctly. The main constituent parts of both mass spectrometers are the thermal ionization source, the cryogenic pump, the analyzer magnet, the flight tube, and the multicollector system. All parts of the mass spectrometers are at high vacuum during analysis. The thermal ionization sources are pumped in order to reach high vacuum $\left(10^{-8}\right.$ mbar) through a system consisting of a rotary pump and a turbomolecular pump. The flight tubes have two ion pumps that guarantee even higher vacuum $\left(10^{-9} \mathrm{mbar}\right)$. For lithium isotope measurements, a double filament configuration was used. This configuration is advantageous for the elements that can be evaporated at low temperature but have a rather high first ionization potential and require a high filament temperature to reach sufficient ion yields. 


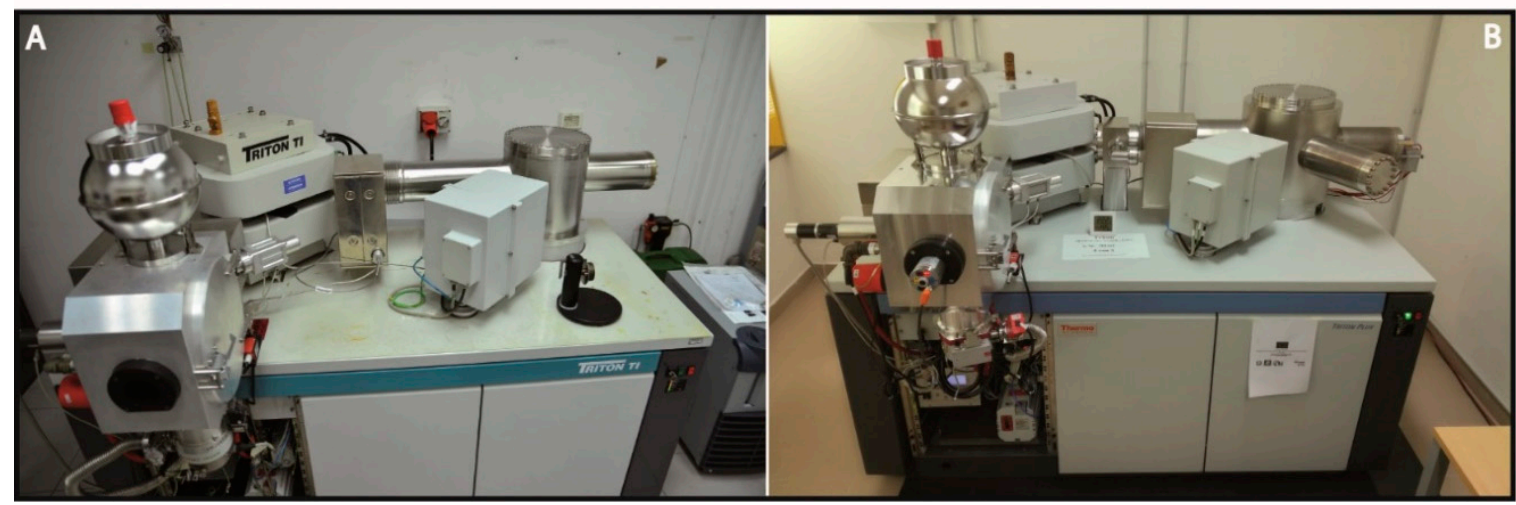

Figure 6. Photograph of the thermal ionization mass spectrometers: (A) the Triton TI at INGV, OV, and (B) the Triton Plus at DiSTAR.

During sample evaporation, the resultant ions are accelerated by applying a high voltage $(10 \mathrm{kV})$ and are collimated into a tight ion beam applying smaller potentials to a series of plates (source lenses), situated between the thermal ionization source and the flight tube. The ion beam proceeds towards the analyzer magnet passing through the flight tube.

The calibration of the magnetic field has been achieved by opportunely varying the magnetic field intensity to find, at first, the peaks of those elements surely present on the rhenium filaments, such as ${ }^{23} \mathrm{Na},{ }^{39} \mathrm{~K},{ }^{187} \mathrm{Re}$ and then to look for the peaks of the loaded Li standard. The separated ion beam arrives at the Faraday cups, which detect the ions as electric charges and have equal response for different ionic masses. The used mass spectrometers have a multicollector detection system, consisting of a maximum of nine collectors, one fixed in the center and other six (Triton Ti) or eight (Triton Plus) placed symmetrically, capable to move with respect to the central one and to each other, with a spatial precision of $10 \mu \mathrm{m}$. The multicollector detection system permits two conditions of running measurements: static or dynamic mode. The static mode consists of simultaneous measurements of all isotopes involved using multiple faraday cups arranged in a fixed configuration. During the acquisition, the magnetic field remains static, and each faraday cup always measures the same isotope. In case of dynamic measurements, the magnetic field changes and shifts different isotopes into the collectors. Lithium isotope ratios determinations have been performed in dynamic mode at the INGV, $\mathrm{OV}$, by acquiring the ${ }^{6} \mathrm{Li}$ and the ${ }^{7} \mathrm{Li}$ isotopes in the fixed, center Faraday cup, and in static mode at DiSTAR, by acquiring ${ }^{6} \mathrm{Li}$ and the ${ }^{7} \mathrm{Li}$ isotopes in the $\mathrm{L} 4$ and $\mathrm{H} 4$ cups, i.e., those located at the most extreme positions with respect to the central one). Figure 7 summarizes step by step the procedure aimed at the isotope ratios determination, starting from sample dissolution and lithium extraction until the analysis by TIMS. 


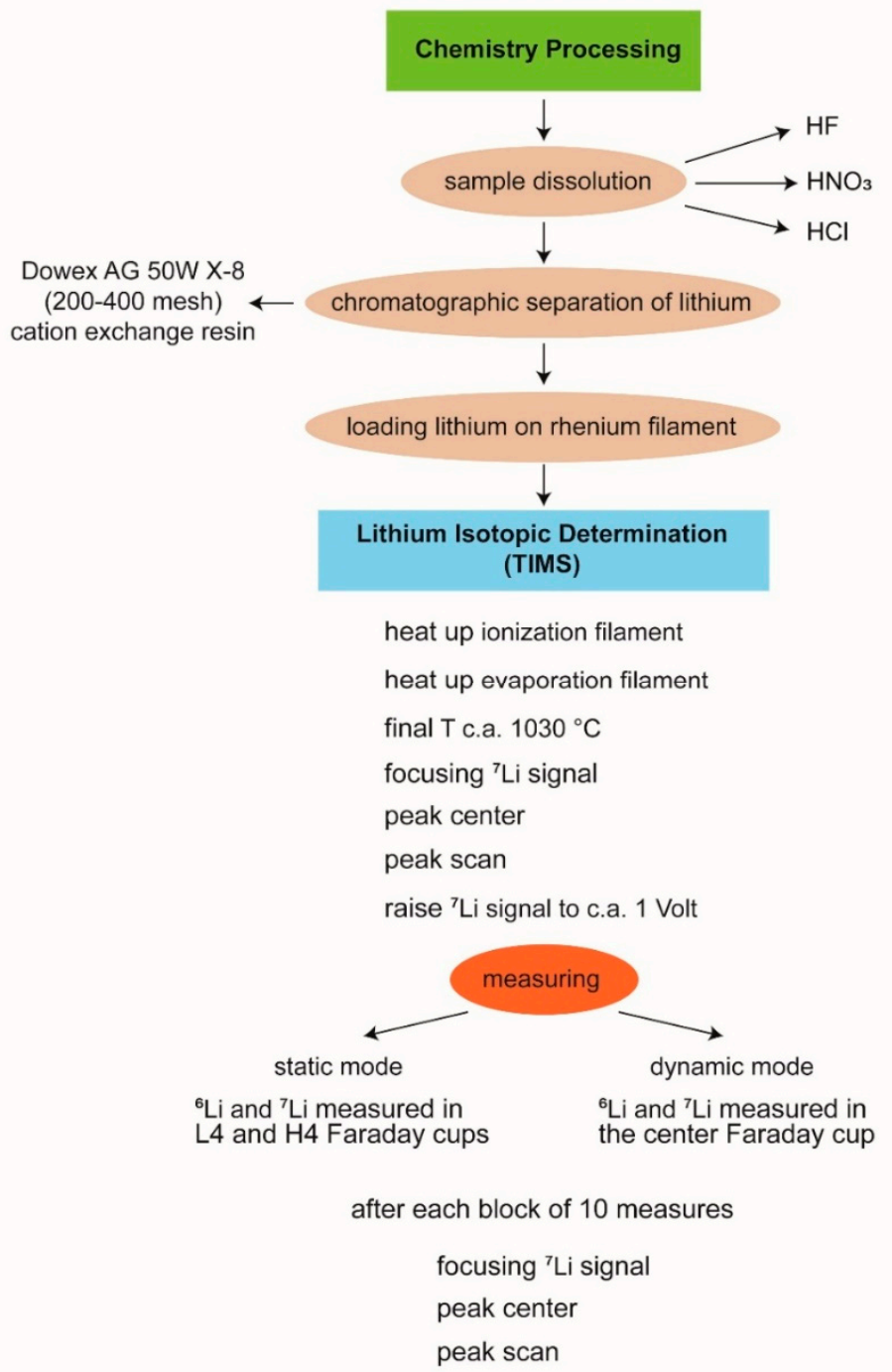

Figure 7. Flow-chart summarizing the procedures adopted for measuring the ${ }^{6} \mathrm{Li} /{ }^{7} \mathrm{Li}$ isotope ratios.

\section{Results}

The running conditions for determining the isotope composition of natural samples were tested by measuring the isotope ratios of NIST L-SVEC standards, the BHVO-2 standard and the seawater reference samples. Several samples were loaded into the turret and placed in the mass spectrometers. After the source vacuum reached c.a. $10^{-8} \mathrm{mbar}$, the current to the ionization filament was raised to a temperature of c.a. $1030^{\circ} \mathrm{C}$ (corresponding to a current of c.a. $1700 \mathrm{~mA}$ ), as recorded by an optical pyrometer, at $100 \mathrm{~mA} / \mathrm{min}$. The evaporation filament current was then increased to $600-800 \mathrm{~mA}$, keeping the temperature at $1030{ }^{\circ} \mathrm{C}$, until a stable ${ }^{7} \mathrm{Li}$ signal of c.a. 1 Volt was achieved.

Usually, when measuring $\mathrm{Sr}$ and $\mathrm{Nd}$ isotopes, specific configurations are adopted to allow the measured ratios to be corrected for the isobaric interference of ${ }^{87} \mathrm{Rb}$ and ${ }^{144} \mathrm{Sm}$. Measured $\mathrm{Sr}$ and $\mathrm{Nd}$ isotope ratios are also corrected for in-run mass fractionation. Since lithium has only two natural isotopes, no special configuration has been used to correct for possible fractionation effects, as well as no correction for isobaric interference phenomenon has been applied.

From June 2018 to May 2019, several measurements of ${ }^{6} \mathrm{Li} /{ }^{7} \mathrm{Li}$ were performed (Table 1). During isotopic measurements, integration times of $10 \mathrm{~s}$ were used for the lithium peaks and $4 \mathrm{~s}$ for the baseline. The final ${ }^{6} \mathrm{Li} /{ }^{7} \mathrm{Li}$ ratios are mean values of 100 acquisitions, divided in 10 blocks of 10 measurements, with focusing and peak centering of the beam between each block. We observed fractionation at the beginning of the measurements in some cases, after 2-4 measurements of the same 
sample in some other cases; in most cases, ${ }^{6} \mathrm{Li} /{ }^{7} \mathrm{Li}$ displayed a plateau, thus permitting the isotope ratios determination. The measured ${ }^{6} \mathrm{Li} /{ }^{7} \mathrm{Li}$ ratios in Table 1 are relative to the measurements performed with fairly stable signals.

Table 1. Isotope analyses performed on natural reference samples and standards.

\begin{tabular}{|c|c|c|c|c|c|}
\hline N. of Analyses & $\begin{array}{l}{ }^{6} \mathrm{Li} /{ }^{7} \mathrm{Li} \text { NIST } \\
\text { L-SVEC INGV }\end{array}$ & ${ }^{6} \mathrm{Li} /{ }^{7} \mathbf{L i} *$ & BHVO-2 & $\begin{array}{c}\text { NA01 } 600 \\
\mathrm{~m}\end{array}$ & $\begin{array}{c}{ }^{6} \mathrm{Li} /{ }^{7} \mathrm{Li} \text { NIST L-SVEC } \\
\text { DiSTAR }\end{array}$ \\
\hline 1 & 0.082522 & 0.082522 & 0.082017 & 0.07982 & 0.082732 \\
\hline 2 & 0.082493 & 0.082493 & & 0.07997 & 0.082668 \\
\hline 3 & 0.082602 & 0.082602 & & 0.08014 & 0.082682 \\
\hline 4 & 0.082600 & 0.082356 & & & 0.082685 \\
\hline 5 & 0.082598 & 0.082509 & & & 0.082643 \\
\hline 6 & 0.082401 & 0.082471 & & & 0.082634 \\
\hline 7 & 0.082365 & 0.082374 & & & 0.082617 \\
\hline 8 & 0.082725 & & & & 0.082618 \\
\hline 9 & 0.082802 & & & & 0.082614 \\
\hline 10 & 0.082840 & & & & 0.082601 \\
\hline 11 & 0.082434 & & & & 0.082476 \\
\hline 12 & 0.082585 & & & & 0.082577 \\
\hline 13 & 0.082675 & & & & 0.082544 \\
\hline 14 & 0.082287 & & & & 0.082212 \\
\hline 15 & 0.082456 & & & & 0.082245 \\
\hline 16 & 0.082525 & & & & 0.082261 \\
\hline 17 & 0.082454 & & & & 0.082869 \\
\hline 18 & 0.082753 & & & & 0.082672 \\
\hline 19 & 0.082775 & & & & 0.082586 \\
\hline 20 & 0.082567 & & & & 0.082769 \\
\hline 21 & 0.082761 & & & & 0.082683 \\
\hline 22 & 0.082743 & & & & \\
\hline 23 & 0.082933 & & & & \\
\hline 24 & 0.082569 & & & & \\
\hline 25 & 0.082637 & & & & \\
\hline 26 & 0.082704 & & & & \\
\hline 27 & 0.082559 & & & & \\
\hline 28 & 0.082356 & & & & \\
\hline 29 & 0.082509 & & & & \\
\hline 30 & 0.082471 & & & & \\
\hline 31 & 0.082374 & & & & \\
\hline 32 & 0.082373 & & & & \\
\hline 33 & 0.082340 & & & & \\
\hline 34 & 0.082327 & & & & \\
\hline 35 & 0.082510 & & & & \\
\hline 36 & 0.082416 & & & & \\
\hline 37 & 0.082673 & & & & \\
\hline 38 & 0.082658 & & & & \\
\hline 39 & 0.082673 & & & & \\
\hline 40 & 0.082629 & & & & \\
\hline 41 & 0.082641 & & & & \\
\hline 42 & 0.082459 & & & & \\
\hline 43 & 0.082398 & & & & \\
\hline${ }^{6} \mathrm{Li} /{ }^{7} \mathrm{Li}_{\text {mean }}$ & 0.082562 & 0.082475 & & 0.079977 & 0.082590 \\
\hline 1sigma & 0.000156 & 0.000086 & & 0.000157 & 0.000168 \\
\hline 2 sigma & 0.000312 & 0.000172 & & 0.000313 & 0.000335 \\
\hline
\end{tabular}

* NIST L-Svec loaded on columns before analyses.

The published values of ${ }^{6} \mathrm{Li} /{ }^{7} \mathrm{Li}$ for NIST L-SVEC and BHVO-2 are 0.082757 and 0.083260 , respectively [39], whereas the isotope ratios of seawater range from 0.080073 to 0.080216 [39]. The analyses made in this work on the NIST L-SVEC lithium standard, in the framework of the 
FIRS 2016 project, are plotted in Figure 8. The mean value of the measured isotope ratios at the INGV, $\mathrm{OV}$, is $0.0826(2 \sigma=0.0003, \mathrm{~N}=50)$, whereas the mean value of the isotope ratios measured at DiSTAR is $0.0826(2 \sigma=0.0003, \mathrm{~N}=21)$. The mean values of isotopic ratios of the lithium standard are calculated considering all measurements performed in the time span during which the project has been carried out, while the error is expressed as $2 \sigma$, where $\sigma$ is the standard deviation among all measurements and represents the external reproducibility [41]. No variations have been found between the ratios measured on the standards passed through the columns and collected before being loaded on filaments and the standards directly loaded.

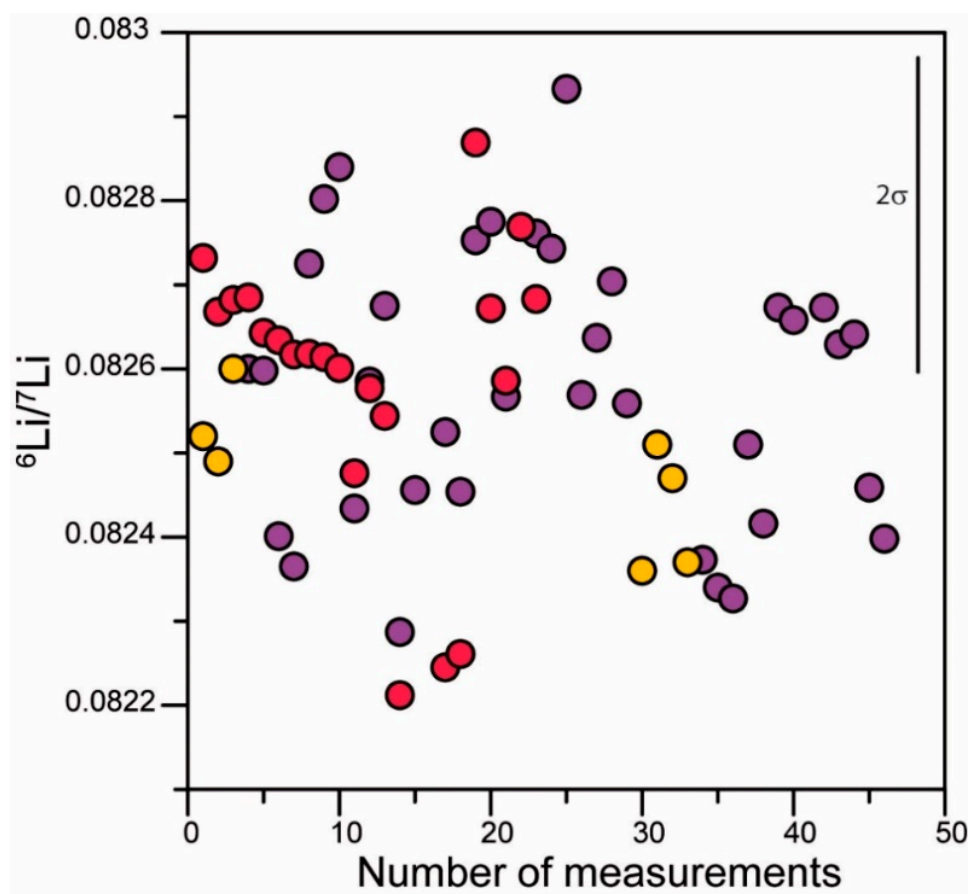

Figure 8. Results of NIST L-SVEC lithium standard measurements at the INGV, OV (purple circles) and DiSTAR (red circles). Orange circles are relative to standards passed through the columns, then collected and loaded on Re filaments.

The measured ${ }^{6} \mathrm{Li} /{ }^{7} \mathrm{Li}$ of the BHVO-2 sample is 0.0820 that in terms of $\delta^{7} \mathrm{Li}$ is $3.43 \%$, whereas aliquots of seawater are characterized by ${ }^{6} \mathrm{Li} /{ }^{7} \mathrm{Li}$ between 0.0799 and 0.0801 that correspond to $\delta^{7} \mathrm{Li}$ from 30.6 to 33.7. These values agree with literature data [39-42].

\section{Discussion and Conclusions}

The abundance in many minerals and its fluid solubility make lithium an element of interest in many deep and surficial environments.

To date, no lithium investigations were performed on groundwaters and volcanic products from the Italian volcanoes to evaluate water-rock interaction and/or magma chamber processes, except for Stromboli volcano. Lithium isotopes were measured on melt inclusions in olivine and on juvenile glassy fragments of ashes erupted at Stromboli volcano to track magma processes and provide evidence about volatile exsolution, separation from the melt and outgassing, diffusion and possible alteration or interaction with hot fluids after the emplacement [22,23]. In these studies, lithium isotope composition was determined by ion probe with a multicollection system at the Pheasant Memorial Laboratory (PML) for Geochemistry and Cosmochemistry, Institute for Study of the Earth's Interior (ISEI), Okayama University at Misasa, Japan.

Prior to the advent of new instruments such as multicollector ICP-MS and Secondary Ion Mass Spectrometry, Thermal Ionization Mass spectrometry was the only method allowing high precision 
during lithium isotope determinations although more time consuming. Based on the results of the literature studies, in the framework of the FISR 2015-2016 "Centro di studio e monitoraggio dei rischi naturali dell'Italia Centrale" project, we carried out a pilot study on the application of the lithium-isotope systematics. In particular, we set up the procedure to be used to extract lithium from natural and reference samples, such as the USGS BHVO-2 (batch \#0759), a seawater sample (NA01 $600 \mathrm{~m}$ ) and the NIST L-SVEC certified international standard and those adopted for measuring lithium isotope compositions by thermal ionization mass spectrometry both in dynamic and static mode. Isotopic ratios have been determined at the INGV-OV using the Finnigan Multicollector Triton $\mathrm{TI}^{\circledR}$ mass spectrometer, in dynamic mode, and at DiSTAR of the University Federico II of Napoli, in static mode, by using the Triton Plus ${ }^{\circledR}$ mass spectrometer. Results are encouraging and may open new research perspectives, acting as a driving factor towards the utilization of the Li-isotope systematics by the research community for future studies aimed at understanding magmatic processes by studying volcanic samples, at modelling water-rock interactions, and at investigating geothermal areas. Several geochemical field campaigns are conducted every year to monitor the volcanic activity of Campi Flegrei, Etna and Stromboli volcanos [43-45], by analyzing the chemical and isotopic composition of free gases and/or gas dissolved in water. In these volcanic areas, lithium isotopes may represent a new tool for research and surveillance. Therefore, we are motivated to unravel possible long- to short-term temporal variability of lithium isotope signature in both mafic minerals and secondary minerals and fluids from the geothermal systems, these latter possibly related to the time-changing contribution of temperature and injected magmatic fluids.

Author Contributions: I.A. and M.L. conceptualized the project. I.A. and F.L. set up the columns for the chemical separation of lithium and performed dissolution, chemical separation and isotopic ratios determinations at INGV, OV. M.L. and L.B. contributed with their expertise to the calibration of the columns and performed the ICP-MS measurements at the INGV, Palermo. M.D. and C.C. participated in discussing the progresses of the project and suggesting possible solutions to specific problems that arose. They performed isotope determinations at the DiSTAR. I.A. wrote the original draft of the paper. All authors reviewed and edited the paper. All authors have read and agreed to the published version of the manuscript.

Funding: This research was funded by FISR-Deliberazione CIPE 71/2016-Progetto “Centro di studio e monitoraggio dei rischi naturali dell'Italia Centrale", sub-project "Lithium isotopes as tracers of crust/mantle interaction at subduction zones; understanding the evolution of the Plio-Quaternary volcanic areas of Central Italy: a pilot study" UR-15, Responsible Dott. Ilenia Arienzo. INGV, OV laboratories have been also financially supported by the EPOS Research Infrastructure through the contribution of the Italian Ministry of University and Research (MUR). Funds for the lithium isotopic determinations at DiSTAR were provided by MIUR 2017 (grant 20178LPCPW_004 to C.C.)

Acknowledgments: The editor and three anonymous reviewers are warmly thanked for their comments and criticism, based on which we revised the first version of the manuscript. Authors warmly thank Ivan Vlastélic from the Observatoire de Physique du Globe de Clermont-Ferrand for his advice and for providing the USGS BHVO-2 sample. Stella Tamburrino, from the Istituto per 1'Ambiente Marino Costiero del Consiglio Nazionale delle Ricerche, is warmly thanked for the NA01 $600 \mathrm{~m}$, water sample. Anna Maiello and Enrico Vertechi are warmly thanked for their support during purchase of the material necessary to the laboratory activity at INGV, OV.

Conflicts of Interest: The authors declare no conflicts of interest. The funders had no role in the design of the study; in the collection, analyses or interpretation of data; in the writing of the manuscript or in the decision to publish the results.

\section{References}

1. Berzelius, J.J. Ein neues mineralisches Alkali und ein neues Metall. J. Chem. Phys. 1817, 21, 44-48.

2. Qi, H.P.; Taylor, P.D.P.; Berglund, M.; Bièvre, P. Calibrated measurement of the isotopic composition and atomic weight of the natural $\mathrm{Li}$ isotopic reference material IRMM-016. Int. J. Mass Spectrom. Ion Proc. 1997, 171, 263-268. [CrossRef]

3. De Laeter, J.R.; Böhlke, J.K.; De Bièvre, P.; Hidaka, H.; Peiser, H.S.; Rosman, K.J.R.; Taylor, P.D.P. Atomic weights of the elements: Review 2000 (IUPAC Technical Report). Pure Appl. Chem. 2003, 75, 683-800. [CrossRef]

4. Tomascak, P.B.; Magna, T.; Dohmen, R. Advances in Lithium Isotope Geochemistry; Springer: Cham, Switzerland, 2016; p. 120. 
5. Penniston-Dorland, S.; Liu, X.M.; Rudnick, R.L. Lithium isotope geochemistry. Rev. Mineral. Geochem. 2017, 82, 165-217. [CrossRef]

6. Chan, L.H.; Edmond, J.M.; Thompson Gillis, K. Lithium isotopic composition of submarine basalts: Implications for the Lithium cycle in the oceans. Earth Planet. Sci. Lett. 1992, 108, 151-160. [CrossRef]

7. Lynton, S.J.; Walker, R.J.; Candela, P.A. Lithium isotopes in the system Qz-Ms-fluid: An experimental study. Geochim. Cosmoch. Acta 2005, 69, 3337-3347. [CrossRef]

8. Wunder, B.; Meixner, A.; Romer, R.L.; Heinrich, W. Temperature-dependent isotopic fractionation of lithium between clinopyroxene and high-pressure hydrous fluids. Contrib. Mineral. Petrol. 2006, 151, 112-120. [CrossRef]

9. Wunder, B.; Meixner, A.; Romer, R.L.; Feenstra, A.; Schettler, G.; Heinrich, W. Lithium isotope fractionation between Li-bearing staurolite, Li-mica and aqueous fluids: An experimental study. Chem. Geol. 2007, 238, 277-290. [CrossRef]

10. Richter, F.M.; Davis, A.M.; DePaolo, D.J.; Watson, E.B. Isotope fractionation by chemical diffusion between molten basalt and rhyolite. Geochim. Cosmochim. Acta 2003, 67, 3905-3923. [CrossRef]

11. Richter, F.M.; Mendybaev, R.A.; Christensen, J.N.; Hutcheon, I.D.; Williams, R.W.; Sturchio, N.C.; Beloso, A.D. Kinetic isotopic fractionation during diffusion of ionic species in water. Geochim. Cosmochim. Acta 2006, 70, 277-289. [CrossRef]

12. Chan, L.H.; Leeman, W.P.; You, C.F. Lithium isotopic composition of Central American Volcanic Arc, lavas: Implications for modification of subarc mantle by slab-derived fluids. Chem. Geol. 1999, 160, 255-280. [CrossRef]

13. Chan, L.H.; Leeman, W.P.; You, C.F. Lithium isotopic composition of Central American volcanic arc lavas: Implications for modification of subarc mantle by slab-derived fluids: Correction. Chem. Geol. 2002, 182, 293-300. [CrossRef]

14. Chan, L.H.; Alt, J.C.; Teagle, D.A.H. Lithium and lithium isotope profiles through the upper oceanic crust: A study of seawater-basalt exchange at ODP Sites 504B and 896A. Earth Planet. Sci. Lett. 2002, 201, 187-201. [CrossRef]

15. Maffre, P.; Goddéris, Y.; Vigier, N.; Moquet, J.S.; Carretier, S. Modelling the riverine $\delta 7$ Li variability throughout the Amazon Basin. Chem. Geol. 2019, 532, 119-336. [CrossRef]

16. Marschall, H.R.; Wanless, V.D.; Shimizu, N.; Pogge von Strandmann, P.A.E.; Elliott, T.; Monteleone, B.D. The boron and lithium isotopic composition of mid-ocean ridge basalts and the mantle. Geoch. Cosmoch. Acta 2017, 207, 102-138. [CrossRef]

17. Moriguti, T.; Nakamura, E. Across-arc variation of Li isotopes in lavas and implications for crust/mantle recycling at subduction zones. Earth Planet. Sci. Lett. 1998, 163, 167-174. [CrossRef]

18. Chan, L.H.; Frey, F.A. Lithium isotope geochemistry of the Hawaiian plume: Results from the Hawaii Scientific Drilling Project and Koolau Volcano. Geochem. Geophys. Geosyst. 2003, 4, 1-20. [CrossRef]

19. Ryan, J.G.; Kyle, P.R. Lithium abundance and lithium isotope variations in mantle sources: Insights from intraplate volcanic rocks from Ross Island and Marie Byrd Land (Antarctica) and other oceanic islands. Chem. Geol. 2004, 212, 125-142. [CrossRef]

20. Elliott, T.; Thomas, A.; Jeffcoate, A.; Niu, Y. Lithium isotope evidence for subduction-enriched mantle in the source of mid-ocean-ridge basalts. Nature 2006, 443, 565-568. [CrossRef]

21. Vlastélic, I.; Koga, K.; Chauvel, C.; Jacques, G.; Télouk, P. Survival of lithium isotopic heterogeneities in the mantle supported by HIMU-lavas from Rurutu Island, Austral Chain. Earth Planet. Sci. Lett. 2009, 286, 456-466. [CrossRef]

22. Schiavi, F.; Kobayashi, K.; Nakamura, E.; Tiepolo, M.; Vannucci, R. Trace element and Pb-B-Li isotope systematics of olivine-hosted melt inclusions: Insights into source metasomatism beneath Stromboli (southern Italy). Contrib. Mineral. Petrol. 2012, 163, 1011-1031. [CrossRef]

23. Schiavi, F.; Kobayashi, K.; Moriguti, T.; Nakamura, E.; Pompilio, M.; Tiepolo, M.; Vannucci, R. Degassing, crystallization and eruption dynamics at Stromboli: Trace element and lithium isotopic evidence from 2003 ashes. Contrib. Mineral. Petrol. 2010, 159, 541-561. [CrossRef]

24. Vlastélic, I.; Staudacher, T.; Bachèlery, P.; Télouk, P.; Neuville, D.; Benbakkar, M. Lithium isotope fractionation during magma degassing: Constraints from silicic differentiates and natural gas condensates from Piton de la Fournaise volcano (Réunion Island). Chem. Geol. 2011, 284, 26-34. [CrossRef] 
25. Weyer, S.; Seitz, H.M. Coupled lithium- and iron isotope fractionation during magmatic differentiation. Chem. Geol. 2012, 294, 42-50. [CrossRef]

26. Chan, L.H.; Gieskes, J.M.; You, C.F.; Edmond, J.M. Lithium isotope geochemistry of sediments and hydrothermal fluids of the Guaymas Basin, Gulf of California. Geochim. Cosmochim. Acta 1994, 58, 4443-4454.

27. Bullen, T.D.; Kharaka, Y.K. Isotopic composition of $\mathrm{Sr}, \mathrm{Nd}$ and $\mathrm{Li}$ in thermal waters from the Norris-Mammoth corridor, Yellowstone National Park and surrounding region. In Proceedings of the 7th International Symposium on Water-Rock Interaction, Park City, UT, USA, 13 July 1992; Balkema Publishers: Rotterdam, The Netherlands, 1992; p. 897.

28. Millot, R.; Petelet-Giraud, E.; Guerrot, C.; Négrel, P. Multi-isotopic composition (d7Li-d11B-dD-d18O) of rainwaters in France: Origin and spatio-temporal characterization. Appl. Geochem. 2010, 25, 1510-1524. [CrossRef]

29. Kloppmann, W.; Chikurel, H.; Picot, G.; Guttman, J.; Pettani, M.; Aharoni, A.; Guerrot, C.; Millot, R.; Gaus, I.; Wintgens, T. B and $\mathrm{Li}$ isotopes as intrinsic tracers for injection tests in aquifer storage and recovery systems. Appl. Geochem. 2009, 24, 1214-1223. [CrossRef]

30. Meredith, K.; Moriguti, T.; Tomascak, P.; Hollins, S.; Nakamura, E. The lithium, boron and strontium isotopic systematics of groundwaters from an arid aquifer system: Implication for recharge and weathering processes. Geochim. Cosmochim. Acta 2013, 112, 20-31. [CrossRef]

31. Pogge von Strandmann, P.A.E.; Porcelli, D.; James, R.H.; van Calsteren, P.; Schaefer, B.; Cartwright, I.; Reynolds, B.C.; Burton, K.W. Chemical weathering processes in the Great Artesian Basin: Evidence from lithium and silicon isotopes. Earth Planet. Sci. Lett. 2014, 406, 24-36. [CrossRef]

32. Négrel, P.; Millot, R.; Guerrot, C.; Petelet-Giraud, E.; Brenot, A.; Malcuit, E. Heterogeneities and interconnections in groundwaters: Coupled B, Li andstable-isotope variations in a large aquifer system (Eocene Sand aquifer, Southwestern France). Chem. Geol. 2012, 296, 83-95.

33. Millot, R.; Négrel, P. Multi-isotopic tracing (d7Li, d11B, 87Sr/86Sr) and chemical geothermometry: Evidence from hydro-geothermal systems in France. Chem. Geol. 2007, 244, 664-678. [CrossRef]

34. Falkner, K.K.; Church, M.; Measures, C.I.; LeBaron, G.; Thouron, D.; Jeandel, C.; Stordal, M.C.; Gill, G.A.; Mortlock, R.; Froelich, P.; et al. Minor and trace element chemistry of lake Baikal, its tributaries, and surrounding hot springs. Limnol. Oceanogr. 1997, 42, 329-345. [CrossRef]

35. Brant, C.; Coogan, L.A.; Gillis, K.M.; Seyfried, W.E.; Pester, N.J.; Spence, J. Lithium and Li-isotopes in young altered upper oceanic crust from the East PacificRise. Geochim. Cosmochim. Acta 2012, 96, 272-293. [CrossRef]

36. Pogge von Strandmann, P.A.E.; Burton, K.W.; James, R.H.; van Calsteren, P.; Gislason, S.R. Assessing the role of climate on uranium and lithium isotope behaviour in rivers draining a basaltic terrain. Chem. Geol. 2010, 270, 227-239. [CrossRef]

37. Tomascak, P.B.; Hemming, N.G.; Hemming, S.R. The lithium isotopic composition of waters from the Mono Basin. California. Geochim. Cosmochim. Acta 2003, 67, 601-611. [CrossRef]

38. Henchiri, S.; Clergue, C.; Dellinger, M.; Gaillardet, J.; Louvat, P.; Bouchez, J. The influence of hydrothermal activityon the Li isotopic signature of rivers draining volcanic areas. Procedia Earth Planet. Sci. 2014, 10, 223-230. [CrossRef]

39. James, R.H.; Palmer, M.R. The lithium isotope composition of international rock standards. Chem. Geol. 2000, 166, 319-326. [CrossRef]

40. Arienzo, I.; Carandente, A.; Di Renzo, V.; Belviso, P.; Civetta, L.; D'Antonio, M.; Orsi, G. Sr and Nd isotope analysis at the Radiogenic Isotope Laboratory of the Istituto Nazionale di Geofisica e Vulcanologia, Sezione di Napoli-Osservatorio Vesuviano. Rapp. Tec. INGV 2013, 260, 1-18.

41. Goldstein, S.L.; Deines, P.; Oelkers, E.H.; Rudnick, R.L.; Walter, L.M. Standards for publication of isotope ratio and chemical data in Chemical Geology. Chem. Geol. 2003, 202, 1-4. [CrossRef]

42. Misra, S.; Froelich, P.N. Measurements of Lithium isotope ratios by quadrupole-ICP-MS: Application to seawater and natural carbonates. J. Anal. At. Spectrom. 2009, 24, 1524-1533. [CrossRef]

43. Paonita, A.; Caracausi, A.; Martelli, M.; Rizzo, A.L. Temporal variations of helium isotopes in volcanic gases quantify pre-eruptive refill and pressurization in magma reservoirs: The Mount Etna case. Geology 2016, 44, 499-502. [CrossRef] 
44. Rizzo, A.L.; Federico, C.; Inguaggiato, S.; Sollami, S.; Tantillo, M.; Vita, F.; Bellomo, S.; Longo, M.; Grassa, F.; Liuzzo, M. The 2014 effusive eruption at Stromboli volcano (Italy): Inferences from soil CO2 flux and $3 \mathrm{He} / 4 \mathrm{He}$ ratio in thermal waters. Geophys. Res. Lett. 2015, 42, 2235-2243. [CrossRef]

45. Cardellini, C.; Chiodini, G.; Frondini, F.; Avino, R.; Bagnato, E.; Caliro, S.; Lelli, M.; Rosiello, A. Monitoring diffuse volcanic degassing during volcanic unrests: The case of Campi Flegrei (Italy). Sci. Rep. 2017, 7, 6757. [CrossRef] [PubMed]

(C) 2020 by the authors. Licensee MDPI, Basel, Switzerland. This article is an open access article distributed under the terms and conditions of the Creative Commons Attribution (CC BY) license (http://creativecommons.org/licenses/by/4.0/). 